\title{
SINTERING AND CHARACTERIZATION OF NEW FORSTERITE CERAMICS
}

\author{
MARIA GOREA ${ }^{a}$, MARIETA-ADRIANA NAGHIUa, ALEXANDRA \\ AVRAM $^{a,{ }^{*}}$, IOAN PETEAN ${ }^{\mathrm{a}}$, MARIA TOMOAIA-COTISEL ${ }^{\mathrm{a}, \mathrm{b}}$
}

\begin{abstract}
This study presents the sintering of new forsterite ceramics (FCs) using nano forsterite powder, obtained by a sol-gel method. The forsterite ceramics were sintered between 1200 and $1450{ }^{\circ} \mathrm{C}$. The resulted forsterite ceramics, namely FC at sintering temperature, $T$, written as $F C(T)$, were characterized by various methods, XRD, AFM, apparent density, porosity and shrinkage. Mechanical properties were determined for FC(1400), with a Young elastic modulus at about $43.84 \mathrm{GPa}$ and nano-indentation hardness at around $3.07 \mathrm{GPa}$. Furthermore, the in vitro biocompatibility of $\mathrm{FC}(1200)$ was evaluated using cell staining with fluorescein diacetate, FDA, assay. The cell viability results confirmed that forsterite ceramic, $\mathrm{FC}(1200)$, promotes cell adhesion and proliferation in cell culture, with no significant cytotoxic effects. These findings strongly recommend the new forsterite ceramics, as potential biomaterials for biomedical applications.
\end{abstract}

Keywords: forsterite ceramics, porosity, density, biocompatibility

\section{INTRODUCTION}

In recent years, both forsterite ceramics [1-7] and forsterite composites [8-10] were found of vital interest due to their potential applications in biomedicine. Therefore, various techniques were developed to synthesize nano-crystalline forsterite powder of high purity [11-20] for various applications,

\footnotetext{
a Babes-Bolyai University, Faculty of Chemistry and Chemical Engineering, Department of Chemical Engineering, Physical Chemistry Center, 11 Arany Janos Str., 400028 Cluj-Napoca, Romania

${ }^{\mathrm{b}}$ Academy of Romanian Scientists, 54 Splaiul Independentei, 050085, Bucharest, Romania

*Corresponding author: aavram@chem.ubbcluj.ro
} 
as bone substitutes and implants $[16,17]$ as well as for drug delivery $[19,20]$, particularly due to its high bioactivity, good mechanical properties and biocompatibility [3, 5-10,15].

In this work, the sintering of new forsterite ceramics (FCs) is reported via nano forsterite powder, synthesized by using a sol-gel method. The forsterite ceramics were fired between 1200 and $1450{ }^{\circ} \mathrm{C}$ and were characterized by various methods including, porosity and mechanical properties. Also, the forsterite ceramic sintered at $1200{ }^{\circ} \mathrm{C}, \mathrm{FC}(1200)$, was investigated in cell culture and demonstrated an excellent biocompatibility.

\section{RESULTS AND DISCUSSION}

\section{New forsterite ceramics}

The forsterite ceramics (FCs) underwent some changes depending on their structural characteristics, like apparent porosity, apparent density, and linear shrinkage as function of the sintering temperatures, 1200, 1300, 1400 and $1450{ }^{\circ} \mathrm{C}$ used in the fabrication process for the obtained FCs, noted FC(1200), FC(1300), FC(1400), and FC(1450).

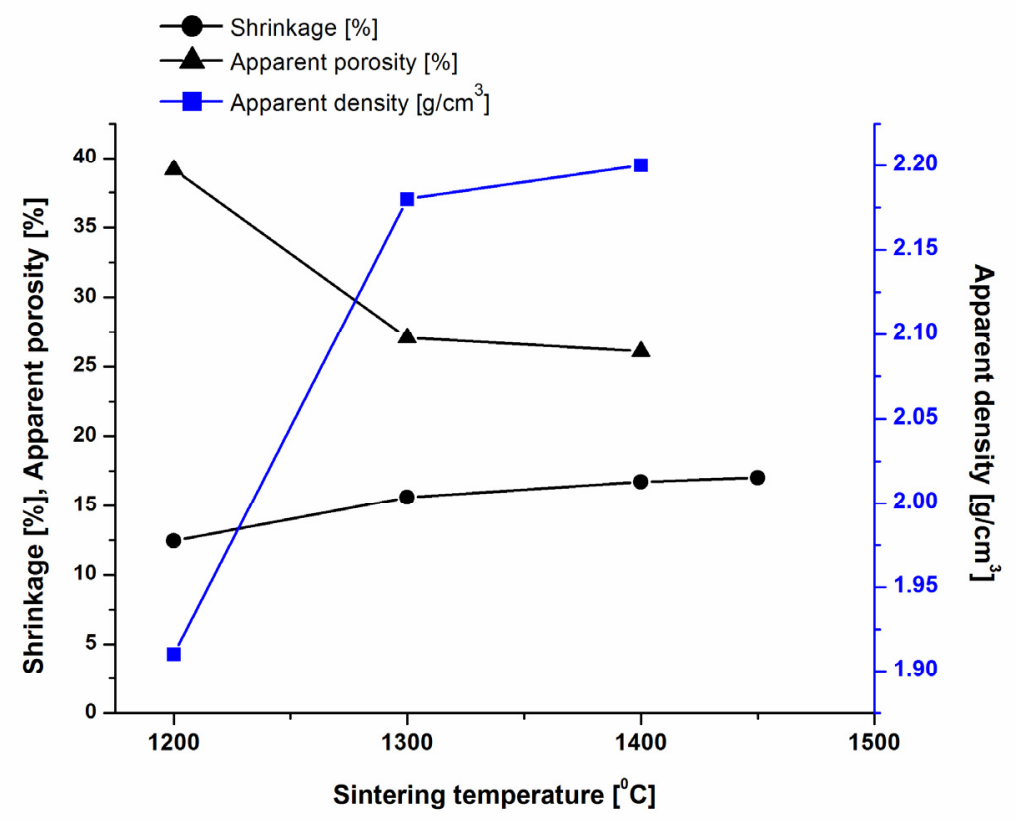

Figure 1. Apparent density, apparent porosity and linear shrinkage determined for forsterite ceramics in function of sintering temperature. 
As shown in Figure 1, the linear shrinkage of the sintered forsterite ceramics displayed a steady increase from $12.46 \pm 0.16 \%$ to $17.03 \pm 0.15 \%$, with an increase in sintering temperature from 1200 to $1450{ }^{\circ} \mathrm{C}$. Apparent density increased from $1.91 \pm 0.02$ to $2.33 \pm 0.01\left(\mathrm{~g} / \mathrm{cm}^{3}\right)$, while the corresponding porosity decreased from $39.15 \pm 0.16$ to $25.05 \pm 0.14 \%$.

Statistical analysis evaluated with GraphPad Prism program showed that increasing the sintering temperature induced an increase in linear shrinkage. Statistically significant differences $(p<0.05)$ evaluated by one-way ANOVA and Bonferroni's multiple comparison test were observed between forsterite ceramics sintered at $1200^{\circ} \mathrm{C}$ versus all the others forsterite ceramics sintered at chosen temperatures. Strong differences were also identified between forsterite ceramics sintered at $1300^{\circ} \mathrm{C}$ versus both ceramics sintered at $1400{ }^{\circ} \mathrm{C}$ and $1450^{\circ} \mathrm{C}$. No significant differences were found between ceramics sintered at $1400{ }^{\circ} \mathrm{C}$ and $1450{ }^{\circ} \mathrm{C}$. The order among forsterite ceramics (FC) is: $F C(1200)<F C(1300)<F C(1400) \approx F C(1450)$. This data, shown in Figure 1, revealed that $\mathrm{FC}(1400)$ is apparently the best regarding high compactness of particles in the forsterite ceramic with potential application for bone repair defects.

Statistically strong differences were also identified between apparent density for forsterite ceramic sintered at $1200{ }^{\circ} \mathrm{C}$ versus all the other forsterite ceramics, $p<0.05$; no significant differences were found among forsterite ceramics sintered at $1300^{\circ} \mathrm{C}, 1400^{\circ} \mathrm{C}$ and $1450{ }^{\circ} \mathrm{C}(p>0.05)$. Therefore, the corresponding value at the highest sintering temperature is not shown in Figure 1. Statistically significant differences $(p<0.05)$ were observed between apparent porosity for forsterite ceramic sintered at $1200^{\circ} \mathrm{C}$ versus the other forsterite ceramics, but without a statistically significant difference between forsterite ceramic fired at $1400^{\circ} \mathrm{C}$ compared to FC-1450, $\mathrm{p}>0.05$; the last value corresponding to $1450{ }^{\circ} \mathrm{C}$ is not shown in Figure 1.

Results obtained for the new forsterite ceramics, fired at temperatures ranging from 1200 to $1450{ }^{\circ} \mathrm{C}$, are comparable with those previously reported [3] for similar forsterite ceramics, fired at higher temperature from 1350 to $1550{ }^{\circ} \mathrm{C}$. Our new forsterite ceramics present the advantage that they were obtained at lower sintering temperatures and demonstrated a unique phase of forsterite structure without a secondary phase of $\mathrm{MgO}$, as revealed by XRD spectra. Also, it is important to emphasize that the forsterite ceramic, $\mathrm{FC}(1200)$, obtained at the lowest sintering temperature, presents the highest porosity and is selected for in vitro biocompatibility evaluation of its scaffolds by using FDA assay in HFL culture. 


\section{Mechanical properties of forsterite ceramic, $\mathrm{FC}(1400)$}

A novelty in the methodological investigation is represented by nanoindentation, used directly for the first time on forsterite ceramic, $\mathrm{FC}(1400)$. The AFM images on $\mathrm{FC}(1400)$ fired at $1400^{\circ} \mathrm{C}$ are presented in Figure 2. The surface topographies revealed a sintered ceramic having square shaped crystal aggregates stacked together into a compact microstructure, Figures 2a and $2 \mathrm{~b}$. The square sides of the aggregates vary from 2 to $4 \mu \mathrm{m}$ and their thickness is around $500 \mathrm{~nm}$.

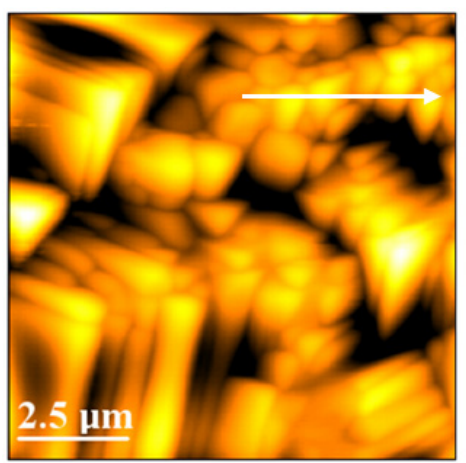

a

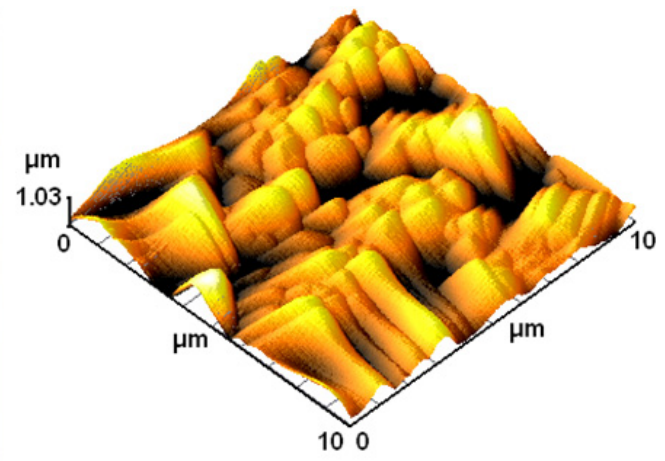

b

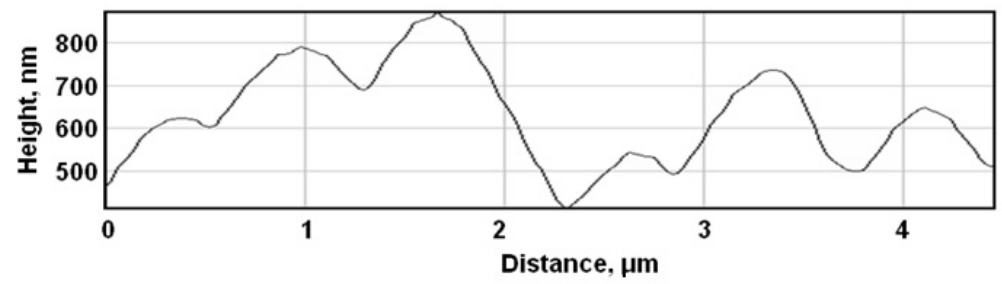

c

Figure 2. AFM images of forsterite ceramic fired at $1400^{\circ} \mathrm{C}$, scanning area $10 \mu \mathrm{m} \times 10 \mu \mathrm{m}$; a) 2D-topography image; b) 3D-topography image; c) cross section on the arrow in panel (a).

Several superficial pores occur due to the close packing of the crystals, visualized in Figure $2 \mathrm{~b}$. They have polyhedral shape with a length situated between $2-3 \mu \mathrm{m}$ and a width of about $1 \mu \mathrm{m}$. The depth of pores depends on their position related to the top of the surface and could achieve about $1.03 \mu \mathrm{m}$. The profile, in Figure $2 \mathrm{c}$, shows the size of crystals with a thickness situated at around $500 \mathrm{~nm}$.

The hardness, $3.07 \pm 0.11 \mathrm{GPa}$ and Young elastic modulus, $43.84 \pm$ $3.29 \mathrm{GPa}$, for forsterite ceramics fired at $1400^{\circ} \mathrm{C}$ temperature were measured 
by means of nanoindentation on the scanned area indicated in Figure 2. The Young elastic modulus is higher than the corresponding values found by others for cortical bone [30]. Therefore, it is reasonable to consider FC(1400) as a good candidate for orthopedic and dental implants.

\section{Cell staining with FDA}

Cell viability in presence of forsterite ceramics fired at $1200^{\circ} \mathrm{C}$ was estimated by FDA assay at 1, 3 and 7 days in cell culture. The results are a measure of cell proliferation rate.

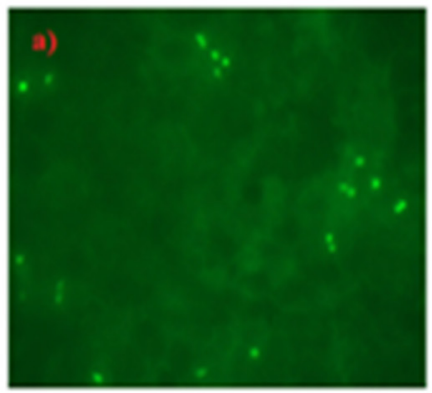

a

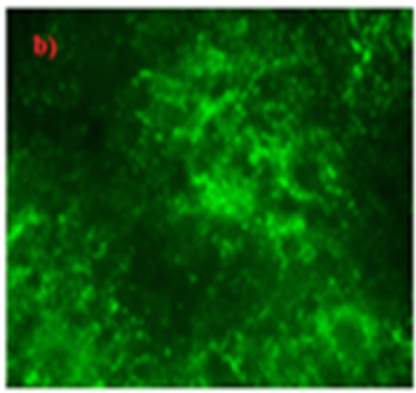

$b$

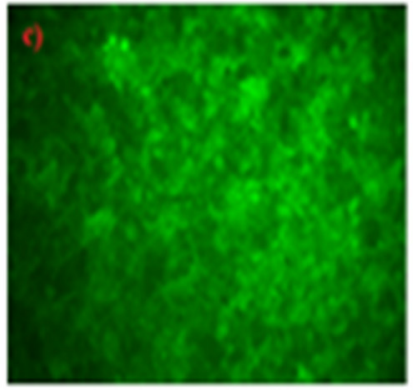

C

Figure 3. Optical microscopy images of FDA stained (in green) HFL after different incubation time, a) 1 day (1d), b) 3d, and c) $7 d$, on the surface of forsterite ceramic scaffolds, fired at $1200^{\circ} \mathrm{C}$.

Following staining with FDA, living cells appear in fluorescent green (Figure 3 ). By increasing the time of maintaining the forsterite ceramic, FC(1200), scaffolds in the culture medium, from 1 to 3 and 7 days, the number of living cells also increased.

The cell proliferation on forsterite ceramic scaffolds confirms that forsterite ceramic promotes the proliferation of human fibroblast cells without a significant cytotoxic effect. So, the forsterite ceramic, FC(1200), scaffolds are thought beneficial for adhesion, growth and proliferation of cells with great impact on biomedical applications

\section{AFM on forsterite ceramic scaffolds}

The AFM images obtained on the forsterite ceramic fired at $1200{ }^{\circ} \mathrm{C}$ are presented in Figure 4. The surface topography is irregular (Figure 4a) due to the presence of pores. The surface of forsterite ceramic, FC(1200), is rather compact, particles being well sintered to one another. This fact is also observed in the phase image where the particles appear in the same shade of brown (Figure 4b). The pores between particles are better evidenced 
in the 3D representation in Figure 4c. The local surface roughness, expressed as RMS [24, 25], of the FC surface is situated at $63 \pm 10 \mathrm{~nm}$, depending on pore size, on a scanned area of $1 \mu \mathrm{m} \times 1 \mu \mathrm{m}$.
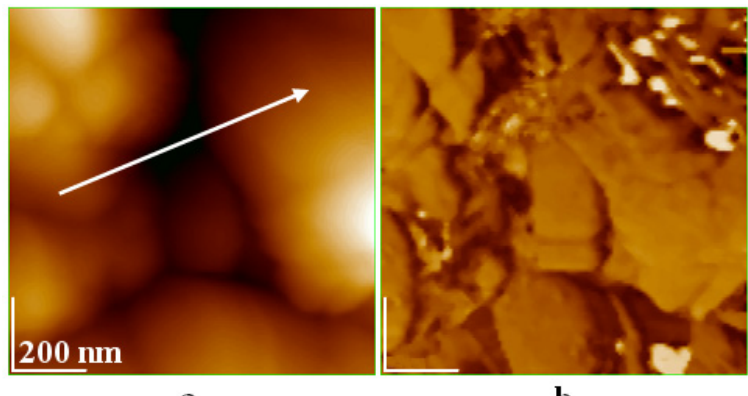

b

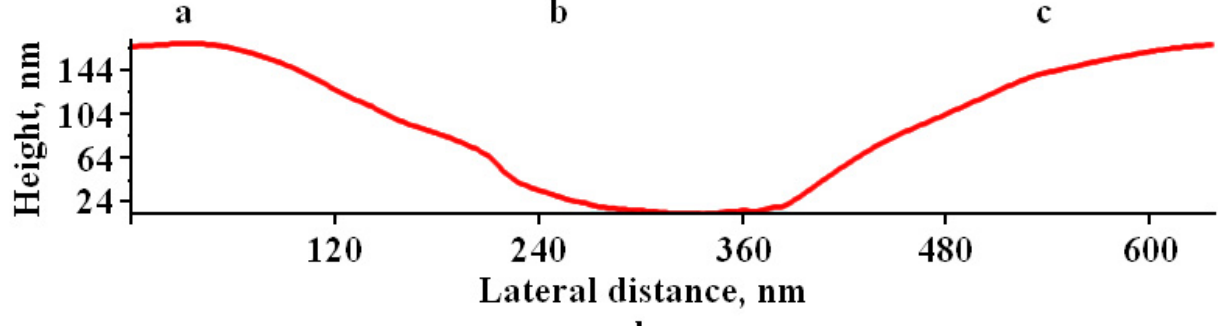

d

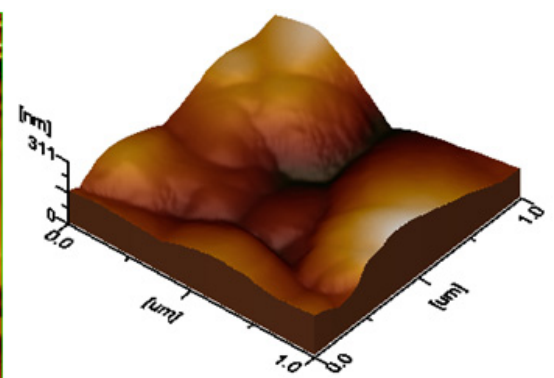

c

Figure 4. The AFM image of forsterite ceramic, FC(1200), a) 2D-topography; b) phase image; c) 3D-topography; d) cross section along the arrow given in panel a)

The size of surface pore is investigated by the surface profile illustrated in Figure 4d. The average depth of the identified pore is around $164 \mathrm{~nm}$. The pore shape is rounded. Therefore, the equivalent diameter of this pore is about $400 \mathrm{~nm}$.

Definitely, the porous surface of scaffolds can promote cell attachment and movement and thus, can support the excellent biocompatibility of forsterite ceramics, FC(1200), as evidenced by FDA staining of fibroblasts (Figure 3).

\section{CONCLUSIONS}

New porous forsterite ceramics were obtained by sintering at 1200 , 1300,1400 and $1450^{\circ} \mathrm{C}$ from nano forsterite powder synthesized by an original sol-gel method, using magnesium nitrate and TEOS as raw materials. The apparent porosity of the four forsterite ceramics, decreased gradually with the increase in sintering temperature from about $39 \%$ at $1200{ }^{\circ} \mathrm{C}$ to $25 \%$ at $1450{ }^{\circ} \mathrm{C}$. The $\mathrm{FC}(1400)$ revealed a rather high hardness of about $3 \mathrm{GPa}$, which recommend this material for biomedical applications as porous implants. 388 
However, mechanical properties need to be better investigated to determine the specificity of these ceramics for clinical applications. Additionally, fosterite ceramics $\mathrm{FC}(1200)$, revealed excellent biocompatibility in HFL culture, as judged by cells staining FDA assay.

Taking into account that nano forsterite structure possesses antimicrobial activity, the new porous forsterite ceramics developed in this work are suitable for antimicrobial applications, serving as carrier for antibiotics. These findings recommend the new porous forsterite ceramics as a good choice for bone repair simultaneously protecting the bone against microbial infections, which are produced especially by staphylococcus aureus.

\section{EXPERIMENTAL SECTION}

\section{Preparation of forsterite ceramics}

Nano forsterite powder was synthesized using $99.5 \%$ pure magnesium nitrate hexahydrate $\left(\mathrm{Mg}\left(\mathrm{NO}_{3}\right)_{2} \cdot 6 \mathrm{H}_{2} \mathrm{O}\right.$, Merck) and tetraethyl orthosilicate $\left(\mathrm{C}_{8} \mathrm{H}_{20} \mathrm{O}_{4} \mathrm{Si}\right.$ - TEOS, Merck) as precursors, following a Mg:Si molar ratio of 2:1. Magnesium nitrate was dissolved in $200 \mathrm{~mL}$ ultrapure water. TEOS was then added. A quantity of sucrose 4 times the previously added amount of TEOS was dissolved in $400 \mathrm{~mL}$ ultrapure water. The dissolved sucrose was added drop by drop into the precursor mixture. The final solution was then homogenized on a magnetic stirrer for 2 hours. Polyvinyl alcohol (PVA) at a ratio of 0.8:1 to the previously used sucrose was added to the homogenized solution. The $\mathrm{pH}$ of the solution was brought to 1 using nitric acid (65\%, Merck) followed by a second homogenization period of 2 hours at room temperature and a third one for another 2 hours at $80^{\circ} \mathrm{C}$. The final mixture was aged for 24 hours at room temperature to allow for gel formation. The formed gel was dried at $100^{\circ} \mathrm{C}$ in an air atmosphere until complete dehydration, resulting in a black, thick gel that was finally thermally treated at $900^{\circ} \mathrm{C}$ for $2 \mathrm{~h}$ with a heating rate of $5^{\circ} \mathrm{C} / \mathrm{min}$.

To obtain forsterite ceramics, the nano forsterite powder was mixed with a aqueous solution of $6 \%$ poly vinyl alcohol (PVA, from Sigma-Aldrich), leading to a granulated mixture, which was pressed into compact pellets, with a diameter of about $6 \mathrm{~mm}$ and a thickness of around $2 \mathrm{~mm}$ at a specific pressure of $500 \mathrm{kgf} / \mathrm{cm}^{2}(49 \mathrm{MPa})$.

Then, the forsterite samples were fired in air at temperatures of 1200 , 1300,1400 and $1450{ }^{\circ} \mathrm{C}$ in a laboratory kiln at a heating rate of $2^{\circ} \mathrm{C} / \mathrm{min}$, for $3 \mathrm{~h}$ plateau, at each sintering temperature. Every experiment was repeated for four times and the data are given as average values \pm SD (standard deviations). For biocompatibility study in cell culture, the same FC pellets were used as FC scaffolds. 


\section{Characterization of forsterite ceramics}

Phase composition. X-Ray Diffraction (XRD). The phase composition of forsterite ceramics was determined using a Bruker D8 Advance diffractometer, with $\mathrm{Co}, \mathrm{K} \alpha_{1}=1.79026 \AA$, operated at $35 \mathrm{kV}$ and $40 \mathrm{~mA}$. The pattern was collected for $2 \vartheta$ range from $5^{\circ}$ and $65^{\circ}$, with a step size of $0.02 \% \mathrm{sec}$ (unpublished results). Phase composition of forsterite ceramics fired from 1200 to $1450{ }^{\circ} \mathrm{C}$ was determined and a unique forsterite phase was detected at all sintering temperatures,

Morphology of FC thin layer. Atomic force microscopy (AFM) imaging was performed in tapping mode, on a Jeol JSPM 4210 scanning probe microscope using a specific cantilever NSC 15 hard produced by Micromasch Co., having a spring constant of $40 \mathrm{~N} / \mathrm{m}$ and a resonant frequency of $325 \mathrm{kHz}$. Different macroscopic areas were investigated at different scanning areas ranging from $5 \mu \mathrm{m} \times 5 \mu \mathrm{m}$ to $1 \mu \mathrm{m} \times 1 \mu \mathrm{m}$. The AFM images were obtained on layers of ceramics prepared similarly as already reported for biomaterials [21-23] and surface roughness was determined by root mean square, RMS, [24, 25].

Compactness characteristics. The compactness characteristics, like apparent density, apparent porosity and shrinkage, were determined by a hydrostatic method, weighing the FC samples in both air and water according to Archimedes' principle [4].

Mechanical properties of forsterite ceramics. Mechanical properties, as Young elastic modulus and hardness, of forsterite ceramic, FC-1400 fired at $1400^{\circ} \mathrm{C}$, were performed by means of a Triboindenter Hysitron TI900 nanoindenter coupled with an atomic force microscope.

Biocompatibility of FC-1200 scaffolds. Biocompatibility of forsterite ceramic scaffolds was determined by cells viability assay [26-29]. Forsterite ceramic, FC(1200), scaffolds (pellets) were subjected to in vitro biocompatibility investigation using fluorescein diacetate, FDA, assay [28] to detect cell adhesion and proliferation in human fibroblast from lung, HFL culture. HFL cells were cultured in standard DMEM medium supplemented with nutrient mixture F-12 HAM medium with 10\% fetal calf serum (FCS) and proper amount of penicillin and streptomycin.

The FDA is an indicator of cell viability, and is the substrate for the intracellular nonspecific esterase. The FDA diffuses freely into cells and is rapidly hydrolysed to fluorescein once it enters within a viable cell. The intensity of fluorescence is dependent on membrane integrity and enzymatic activity of the cells, so the fluorescent signals are proportional with the number of viable cells. 
Briefly, the $2 \times 10^{5} \mathrm{HFL}$ cells were seeded in each well of the 24 -well plates, namely in complete DMEM medium/well on the surface of each FC(1200) scaffold. After $1 d, 3 d$ and $7 d$, the cell viability (adhesion and proliferation of cells) was analysed using FDA assay. Cells were incubated 5 min in dark at $37^{\circ} \mathrm{C}$ with $1 \mathrm{~mL} /$ well of FDA solution (at a final concentration of $2.4 \mathrm{mM}$ in phosphate buffer saline, PBS) supplemented with $\mathrm{Ca}^{2+}$ and $\mathrm{Mg}^{2+}$. After incubation the wells were washed twice with PBS, and viable fluorescent cells adhered on scaffolds were visualized with the Zeiss Axio Observer D1 inverted fluorescence microscope with 200x magnification lens, using a $488 \mathrm{~nm}$ excitation filter. Images were captured with a CCD camera (Axiocam MRM) and analyzed using Axiovision Release 4.6.3 software.

Cell adhesion and proliferation were evaluated after cell seeding at $1 d, 3 d$ and 7 days, by FDA assay. The results from fluorescein diacetate staining were also validated by MTT assay. At 14 days in cell culture, the cells viability was high but not significant higher than the cells activity at 7 days in cells culture, indicating that an optimal viability is reached already at 7 days.

Statistical analysis. GraphPad Prism 5 was used for statistical analysis. All data are given as the mean value \pm standard deviation (SD) of at least four independent experiments. Significant differences were identified using the oneway ANOVA and Bonferroni's multiple comparison test. Differences among samples were considered statistically significant if $p<0.05$, or otherwise stated.

\section{ACKNOWLEDGEMENTS}

One of the authors, Alexandra Avram would like to thank the Executive Agency for Higher Education, Research, Development and Innovation Funding (UEFISCDI) for financial support through grant no. 83. All authors would like to thank D. Frankel for assistance with nanoindentation used to determine mechanical properties of forsterite ceramics.

\section{REFERENCES}

1. F. Tavangarian; R. Emadi; Mater.Lett., 2011, 65(4), 740-743.

2. S. Oh; N. Oh; M. Appleford; J. L. Ong; Am. J. Biochem. Biotechnol., 2006, 2(2), 49-56.

3. S. Ni; L. Chou; J. Chang; Ceram. Int., 2007, 33(1), 83-88.

4. K. Y. S. Lee; K. M. C. Chin; S. Ramesh; J. Purbolaksono; M. A., Hassan; M. Hamdi; W. D. Teng; J. Ceram. Process. Res., 2013, 14(1), 131-133.

5. M. Kharaziha; M. H. Fathi; J. Mech. Behav. Biomed. Mater., 2010, 3(7), 530-537.

6. M. Saqaei; M. Fathi; H. Edris; V. Mortazavi; N. Hosseini; Adv. Powder Technol., 2016, 27(5), 1922-1932.

7. A. Krajewski; A. Ravaglioli; E. Roncari; P. Pinasco; L. Montanari; J. Mater. Sci.: Mater. Med., 2000, 11(12), 763-771.

8. M. Saqaei; M. Fathi; H. Edris; V. Mortazavi; Mat. Sci. Eng. C, 2015, 56, 409-416. 
MARIA GOREA, MARIETA-ADRIANA NAGHIU, ALEXANDRA AVRAM, IOAN PETEAN, MARIA TOMOAIA-COTISEL

9. G. Furtos; M. A. Naghiu; H. Declercq; M. Gorea; C. Prejmerean; O. Pana; M. Tomoaia-Cotisel; J. Biomed. Mater. Res. Part B, Appl. Biomat., 2016, 104(7), 1290-1301.

10. S. Naghieh; E. Foroozmehr; M. Badrossamay; M. Kharaziha; Mater. Des., 2017, 133, 128-135.

11. R. Choudhary; P. Manohar; J. Vecstaudza; M .J. Yáñez-Gascón; H. Pérez Sánchez; R. Nachimuthu; J. Locs; S. Swamiappan; Mater. Sci. Eng. C, 2017, 77, 811-822.

12. M. Zabihi; M. R. Ayatollahi; H.R.Rezaie; Theor. Appl. Fract. Mech., 2018, 94, 173-180.

13. H. Ghomi; M. Jaberzadeh; M. H. Fathi; J. Alloys Compd., 2011, 509(5), L63-L68.

14. S. M. Mirhadi; A. Forghani; F. Tavangarian; Ceram. Int., 2016, 42(7), 7974-7979.

15. M. A. Naghiu; M. Gorea; E. Mutch; F. Kristaly; M. Tomoaia-Cotisel, J. Mater. Sci. Techol., 2013, 29(7), 628-632.

16. M. A. Naghiu; M. Gorea; F. Kristaly; M. Tomoaia-Cotisel; Ceram-Silikaty, 2014, 58(4), 303-307.

17. M. Gorea; M. A. Naghiu; M. Tomoaia-Cotisel; G. Borodi; Ceram-Silikaty, 2013, 57(2), 87-91.

18. Y. Xie; W. Zhai; L. Chen; J. Chang; X. Zheng; C. Ding; Acta Biomater., 2009, 5(6), 2331-2337.

19. R. Choudhary; A. Chatterjee; S. K. Venkatraman; S. Koppala; J. Abraham; S. Swamiappan; Bioact. Mater., 2018, 3(3), 218-224.

20. A. Danistean; M. Gorea; A. Avram; S. Rapuntean; Gh. Tomoaia; A. Mocanu; C. Garbo; O. Horovitz; M. Tomoaia-Cotisel; Studia Chem., 2016, 61(3), 275-283.

21. F. Goga; E. Forizs; A. Avram; A. Rotaru; A. Lucian; I. Petean; A. Mocanu; M. Tomoaia-Cotisel; Rev. Chim. (Bucharest), 2017, 68(6), 1193-1200.

22. F. Goga; E. Forizs; G. Borodi; Gh. Tomoaia; A. Avram; R. Balint; A. Mocanu; O. Horovitz; M. Tomoaia-Cotisel; Rev. Chim. (Bucharest), 2017, 68(12), 2907-2913.

23. Gh. Tomoaia; M. Tomoaia-Cotisel; L. B. Pop; A. Pop; O. Horovitz; A. Mocanu; N. Jumate; L. D. Bobos; Rev. Roum. Chim., 2011, 56(10-11), 1039-1046.

24. P. T. Frangopol; D. A. Cadenhead; Gh. Tomoaia; A. Mocanu; M. TomoaiaCotisel; Rev. Roum.Chim., 2015, 60(2-3), 265-273.

25. U. V. Zdrenghea; Gh. Tomoaia; D.-V. Pop-Toader; A. Mocanu; O. Horovitz; M. Tomoaia-Cotisel; Comb. Chem. High Throughput Screen., 2011, 14(4), 237-247.

26. Gh. Tomoaia; O. Soritau; M. Tomoaia-Cotisel; L. B. Pop; A. Pop; A. Mocanu; O. Horovitz; L. D. Bobos; Powder Technol., 2013, 238, 99-107.

27. Gh. Tomoaia; A. Mocanu; I. Vida-Simiti; N. Jumate; L. D. Bobos; O. Soritau; M. Tomoaia-Cotisel; Mat.Sci. Eng. C, 2014, 37, 37-47.

28. S. Rapuntean; P. T. Frangopol; I. Hodisan; Gh. Tomoaia; D. Oltean-Dan; A. Mocanu; C. Prejmerean; O. Soritau; L. Z. Racz; M. Tomoaia-Cotisel; Rev. Chim. (Bucharest), 2018, 69(12), 3537-3544.

29. D. Dufrane; C. Delloye; I. J. Mckay; P. N. De Aza; S. De Aza; Y. J. Schneider; M. Anseau; J. Mater. Sci. Mater. Med., 2003, 14(1), 33-38.

30. J. Y. Rho; R. B. Ashman; C. H. Turner; J. Biomech., 1993, 26(2),111-119. 